\title{
Is Zuspan Regimen Adequate for Preventing Eclampsia?: A Case Report
}

\author{
Raymond Surya, Budi Iman Santoso, Surahman Hakim \\ Department of Obstetrics and Gynecology, Faculty of Medicine Universitas Indonesia \\ Dr. Cipto Mangunkusumo Hospital Jakarta, Indonesia
}

\begin{abstract}
Magnesium sulphate (MgSO4) is believed to treat preeclampsia and eclampsia for more than a century with a total dose of MgSO4 varying from 2 to 5 g per 24 hours. Zuspan and Pritchard are two internationally recommended regimens that are accepted as the standard regimen.

In this case report, we presented a 41 year old woman with puerperal preeclampsia prescribed with a complete Zuspan regimen. She had eclamptic seizure after completing Zuspan regimen with Mg SO4 level of $4.3 \mathrm{mg} / \mathrm{dL}$.

In this case, the possibility of eclamptic seizures might be due to a lack of MgSO4 dose. The administration of MgSO4 for preeclampsia with severe features and prophylactic of eclampsia should be adjusted.
\end{abstract}

Keywords: Eclampsia, MgSO4, Pritchard, Zuspan

\section{Introduction}

Hypertensive disorders of pregnancy are the second leading cause of maternal morbidity $(12.9 \%)$ and mortality (14\%) in both high and middle-low income countries. ${ }^{1}$ Based on the SOGC Clinical Practice Guideline, preeclampsia is defined as a gestational hypertension with one or more of the following new proteinuria, with one or more adverse conditions or complications. Meanwhile, preeclampsia with severe features means preeclampsia with one or more severe complications. Eclampsia is defined as a generalized seizure in a patient with preeclampsia without previous history of epilepsy. ${ }^{2-4}$ In middle-low income countries, the incidence of eclampsia ranged from 16 to 69 per 10,000, compared with the European countries that is around 2-3 births per $10,000 .^{5}$

Magnesium sulphate (MgSO4) is believed to have been used for the treatment of preeclampsia and eclampsia for more than a century, before it became the first anticonvulsant choice to prevent and control eclamptic events. ${ }^{6}$ In the beginning, the total dose of Mg SO4 to treat preeclampsia and eclampsia varied from 2 to $5 \mathrm{~g}$ per 24 hours. Studies have shown good control of convulsion for variation in regimen, route of administration, and total dose of $\mathrm{MgSO} 4$ as both prophylaxis and treatment., ${ }^{7,8}$ However, the mechanism of action was still poorly understood.

Currently, two recommended standard regimens such as Zuspan and Pritchard regimens have been internationally accepted. The Zuspan regimen includes a loading dose of $4 \mathrm{~g}$ IV and maintenance dose of $1 \mathrm{~g} /$ hour IV, while the Pritchard regimen consists of a loading dose of $4 \mathrm{~g}$ IV and $10 \mathrm{~g} \mathrm{IM}$, followed by a maintenance dose of $5 \mathrm{~g}$ IM per 4 hours. Another regimen frequently used is the Sibai regimen. The Sibai regimen uses $6 \mathrm{~g}$ loading dose and continued with $2 \mathrm{~g}$ /hours. Although these trials revealed the comparable clinical efficacy form of predominantly intravenous (Zuspan or Sibai) and intramuscular (Pritchard) regimens, the minimum effective dose for magnesium to prevent eclampsia is still questionable. ${ }^{9,10}$

In Indonesia, especially in our centre at Department of Obstetrics and Gynecology, Persahabatan Hospital/Faculty of Medicine Universitas Indonesia, we use the Zuspan regimen for severe preeclampsia and eclampsia. This case report presented the application of Zuspan regimen in preeclampsia with severe features that became an eclamptic event.

\section{Case Illustration}

A 41-year-old pregnant woman, was referred to our outpatient clinic at the tertiary hospital due to preeclampsia without severe features, e.g. blood pressure of $140 / 90 \mathrm{mmHg}$ and +1 proteinuria. In our clinic, the patient was re-assessed as 27 weeks of gestational hypertension and she was advised to antenatal control regularly. Due to caesarean

Correspondence: Raymond Surya, Department of Obstetrics and Gynecology, Faculty of Medicine Universitas Indonesia/ Dr. Cipto Mangunkusumo Hospital Jakarta, Indonesia, Email: raymond_s130291@yahoo.co.id 
section (C-section) in previous deliveries, she planned to terminate her pregnancy at 37 weeks' gestational age by elective C-section in February 2018. Of note, her body mass index before pregnancy was 31.2 . The patient was regularly checked for her pregnancy as advised, and no deterioration in her gestational hypertension was found until due.

After performing C-section, the blood pressure raised to $190 / 120 \mathrm{mmHg}$ with +2 proteinuria. We diagnosed as puerperal preeclampsia with severe feature. We administered the loading dose of MgSO4 40\% $4 \mathrm{~g}$ continued by $1 \mathrm{~g}$ per hour as maintenance. Anti-hypertension was prescribed to reach the target of blood pressure of less than $160 \mathrm{mmHg}$ for systolic and $110 \mathrm{mmHg}$ for diastolic. After 24 hours of MgSO4 40\% infusion, we stopped the MgSO $40 \%$ and the patient had a seizure 4 hours later. We examined her magnesium level and the result was $4.3 \mathrm{mg} / \mathrm{dL}$. The patient was diagnosed as puerperal eclampsia and she got the repeated dose of MgSO4 40\% 1g/hour for 24 hours. After that, there was no convulsion anymore and she was discharged six days after the C-section.

\section{Discussions}

Magnesium sulphate has been proven effective to decrease eclamptic convulsion for almost 50\%. ${ }^{11,12}$ Apart from that, Magpie Trial stated that the use of MgSO4 for women with preeclampsia is associated with the $16 \%$ decrease risk of death or serious morbidity related to preeclampsia in 2-3 years later. However, this trial did not find any clear difference in relationships including cardiovascular and stroke morbidity and mortality in later life. In fact, intervention to improve outcome following preeclampsia would increase the longer-term outcome for the women. ${ }^{9}$

Based on literature, the validity of therapeutic range is between $4.8-9.6 \mathrm{mg} /$ $\mathrm{dL}(2.0-3.95 \mathrm{mmol} / \mathrm{L})$, however, result is debatable.Inourcasereport, theadministration of MgSO4 based on Zuspan regimen showed a magnesium level of $4.3 \mathrm{mg} / \mathrm{dL}(1.77 \mathrm{mmol} / \mathrm{L})$, which is a little bit under therapeutic level. After administration of MgSO4, around 40\% of plasma magnesium is protein bound. Meanwhile, the unbound magnesium ion will diffuse into the extravascular-extracellular space into the bone, and across the placenta and fetal membrane, into the fetus and amniotic fluid. The level will reach a constant value after three to four hours' administration i.e. between 0.250 and $0.442 \mathrm{~L} / \mathrm{kg}^{12}$

In a systematic review by Okusanya et al. ${ }^{13}$, the baseline serum magnesium concentration is consistently $<1 \mathrm{mmol} / \mathrm{L}$. An intravenous loading dose of 4-6 grams of MgSO4 is associated with a rapid doubling of baseline within $1 / 2$ hour of starting the injection. Maintenance of $1 \mathrm{~g}$ /hour following a $4 \mathrm{~g}$ loading dose resulted ina mean concentration of magnesium between 1-2 $\mathrm{mmol} / \mathrm{L}$ with fewer fluctuations during the period of administration. Several other studies using the Sibai regimen showed that the steady state of magnesium after giving $2 \mathrm{~g}$ /hour for maintenance is $2-3 \mathrm{mmol} / \mathrm{L}$.

In the Pritchard regimen, the intermittent bolus injection would result a spike in serum concentration that fell rapidly within 2 hours of injection. Therefore, it made more fluctuations compared with the continuous intravenous maintenance regimen. The mean values reached $\geq 2.00 \mathrm{mmol} / \mathrm{L}$, but it did not reach 3.00 $\mathrm{mmol} / \mathrm{L}$. The Zuspan regimen which is used in our centre shows the minimum effective serum magnesium concentration is lower than the therapeutic window. ${ }^{9,14}$ The Sibai regimen should become a choice for maintaining the concentration of magnesium appropriate with the therapeutic level. However, the close monitoring of magnesium concentration level should be performed due to the narrow margin of safety between therapeutic and toxic level of magnesium sulphate. The study by Rebecca G, et al. ${ }^{15}$ showed that there is a low rate of complications due to $\mathrm{MgSO}$. Maternal respiratory depressions occur in $1.3 \%$ of cases (range from 0 to $8.2 \%$ ), calcium gluconate is used less than $0.2 \%$, and only one maternal death is due to MgSO4 (related with a serum level more than $24 \mathrm{mEq} / \mathrm{L}$ ).

The MgSO4 treatment is influenced by body mass index (BMI) and its failure might be due to high BMI. ${ }^{16,17}$ The patient in this case had BMI $31.2 \mathrm{~kg} / \mathrm{m}^{2}$ before pregnancy, was classified as obesity grade II based on Asia Pacific criteria. Women with high BMI have lower circulating levels of $\mathrm{Mg}$ and it remains subtherapeutic up to 18 hours. Around 40\% of circulating $\mathrm{Mg}$ is protein bound and the unbound fraction diffuses into extravascularextracellular spaces. In pregnant women, the distribution of MgSO 4 reaches a plateau value (2.5-4.4 mg/dL) between the third and fourth hours. The doses should be larger for women with BMI exceeding $35 \mathrm{~kg} / \mathrm{m}^{2}$, especially in antepartum because it must be distributed into products of conceptus before reaching the equilibrium. They suggested close monitoring 
among the perioperative period due to the high rate of post-cesarean seizures, especially women with high BMI. Apart from that, the creatinine level should be considered because urinary excretion of $\mathrm{Mg}$ is the major route of metabolic clearance.

Learning from this case, we recommended that the administration of $\mathrm{MgSO} 4$ should be used along with the Sibai regimen for women with high BMI or obese women that consisted of $6 \mathrm{~g} \mathrm{MgSO} 4$ loading dose and continued with 2g/hours. In undertaking MgSO4 for special population with higher doses, the clinician should pay more attention by checking the $\mathrm{Mg}$ level to minimize the toxic potency.

In conclusion, the eclamptic event in this case is possible due to the suboptimal of MgSO4 dose in using the hospital standard of Zuspan regimen. Administration of $\mathrm{MgSO} 4$ for preeclampsia with severe feature and prophylactic of eclampsia should be adjusted to the body mass index.

\section{References}

1. Say L, Chou D, Gemmill A, Tunçalp Ö, Moller A-B, Daniels J, et al. Global causes of maternal death: a WHO systematic analysis. Lancet Glob Health. 2014;2(6):e323-33.

2. Magee LA, Pels A, Helewa M, Rey E, von Dadelszen P, Canadian Hypertensive Disorders of Pregnancy Working Group. Diagnosis, evaluation, and management of the hypertensive disorders of pregnancy: executive summary. J Obstet Gynaecol Can JOGC J Obstet Gynecol Can JOGC. 2014;36(5):416-41.

3. National Institute for Health and Care Excellence (NICE). Hypertension in Pregnancy. Clinical guideline [CG107]. London: NICE; 2010.

4. Hypertension in Pregnancy: Executive Summary. Obstet Gynecol. 2013;122(5):1122.

5. Duley L. The global impact of preeclampsia and eclampsia. Semin Perinatol. 2009;33(3):130-7.

6. WHO. WHO recommendations for prevention and treatment of preeclampsia and eclampsia [Internet]. WHO. [cited 2018 Aug 27]. Available from: http://www.who.int/reproductivehealth/ publications / maternal_perinatal_ health/9789241548335/en/

7. Duley L, Gülmezoglu AM, HendersonSmart DJ, Chou D. Magnesium sulphate and other anticonvulsants for women with pre-eclampsia. Cochrane Database Syst
Rev. 2010;(11):CD000025.

8. Pratt JJ, Niedle PS, Vogel JP, Oladapo OT, Bohren M, Tunçalp Ö, et al. Alternative regimens of magnesium sulfate for treatment of preeclampsia and eclampsia: a systematic review of non-randomized studies. Acta Obstet Gynecol Scand. 2016;95(2):144-56.

9. Magpie Trial Follow-Up Study Collaborative Group. The Magpie Trial: a randomised trial comparing magnesium sulphate with placebo for pre-eclampsia. Outcome for women at 2 years. BJOG Int J Obstet Gynaecol. 2007;114(3):300-9.

10. Sibai BM, Graham JM, McCubbin JH. A comparison of intravenous and intramuscular magnesium sulfate regimens in preeclampsia. Am J Obstet Gynecol. 1984;150(6):728-33.

11. Euser AG, Cipolla MJ. Magnesium sulfate treatment for the prevention of eclampsia: A brief review. Stroke J Cereb Circ. 2009;40(4):1169-75.

12. Salinger DH, Mundle S, Regi A, Bracken $\mathrm{H}$, Winikoff $\mathrm{B}$, Vicini $\mathrm{P}$, et al. Magnesium sulphate for prevention of eclampsia: are intramuscular and intravenous regimens equivalent? A population pharmacokinetic study. BJOG Int J Obstet Gynaecol. 2013;120(7):894-900.

13. Okusanya BO, Oladapo OT, Long Q, Lumbiganon P, Carroli G, Qureshi Z, et al. Clinical pharmacokinetic properties of magnesium sulphate in women with preeclampsia and eclampsia. BJOG Int J Obstet Gynaecol. 2016;123(3):356-66.

14. The Eclampsia Trial Collaborative Group. Which anticonvulsant for women with eclampsia? Evidence from the Collaborative Eclampsia Trial. The Lancet. 1995;345(8963):1455-63.

15. Gordon R, Magee LA, Payne B, Firoz T, Sawchuck D, Tu D, et al. Magnesium sulphate for the management of preeclampsia and eclampsia in low and middle income countries: a systematic review of tested dosing regimens. J Obstet Gynaecol Can. 2014;36(2):154-63.

16. Dayicioglu V, Sahinoglu Z, Kol E, Kucukbas $M$. The use of standard dose of magnesium sulphate in prophylaxis of eclamptic seizures: do body mass index alterations have any effect on success? Hypertens Pregnancy. 2003;22(3):257-65.

17. Anderson JK, Boyd CI. Effect of Maternal Body Mass Index on Serum Magnesium Levels Given for Seizure Prophylaxis. Obstet Gynecol. 2013;122(2 PART 1):394. 